\title{
ESTRUTURA GENÉTICA DE POPULAÇÕES DE MELHORAMENTO DE PINUS CARIBAEA VAR. HONDURENSIS POR MEIO DE MARCADORES MICROSSATÉLITES $\left({ }^{1}\right)$
}

\author{
RODRIGO DE ANDRADE FURLAN $\left({ }^{2}\right)$; EDSON SEIZO MORI $\left({ }^{3}\right)$; EVANDRO VAGNER TAMBARUSSI $\left({ }^{4}\right)$; \\ CRISTIANO BUENO DE MORAES $\left({ }^{4}\right)$; FREDERICO ALMEIDA DE JESUS $\left({ }^{5}\right)$; $\operatorname{LÉO~ZIMBACK~}\left({ }^{6}\right)$
}

\begin{abstract}
RESUMO
O Pinus caribaea var. hondurensis Barret \& Golfari tem elevada importância como espécie comercialmente plantada; aproximadamente 1,8 milhões de hectares estão ocupados por plantios desta espécie no Brasil. O trabalho teve como objetivo verificar por meio de marcadores microssatélites a variabilidade genética em Pinus caribaea var. hondurensis, bem como sua manutenção durante o processo de melhoramento genético, dentro de uma população- base de melhoramento, uma população de matrizes selecionadas e uma população melhorada $\mathrm{F}_{1}$. Para a realização das análises foi necessária a transferência de primers desenvolvidos para locos microssatélites de outras espécies do gênero. Dos 20 pares de primers testados, 8 foram transferidos para a espécie (RPS 25b, RPS 150, PSM 2, PR 4.6, PtTX 2037, PtTX 3029, RPTest 01 e RPTest 09). Verificou-se a existência de endogamia entre e dentro das populações estudadas, e o maior valor observado entre as populações foi $\mathrm{F}_{\mathrm{ST}}=0,0213$ (população base e $\mathrm{F}_{1}$ ). A heterozigosidade média observada e a heterozigosidade esperada na população-base foram, respectivamente, $\mathrm{H}_{0}=0,2469$ e $\mathrm{H}_{\mathrm{e}}=0,2489$. A maior distância genética $(\mathrm{D}=0,0119)$ foi observada entre as populações-base e a população melhorada $F_{1}$. Através da distância genética entre as matrizes, foram indicados 10 cruzamentos potenciais entre as matrizes mais contrastantes, almejando a obtenção de vigor de híbrido nas progênies obtidas a partir destes cruzamentos.
\end{abstract}

Palavras-chave: Parâmetros genéticos, marcadores genéticos, DNA e polinização controlada.

\section{ABSTRACT \\ GENETIC STRUCTURE IN BREEDING POPULATIONS OF PINUS CARIBEAE VAR. HONDURENSIS BY SSR MARKERS.}

The Pinus caribaea var. hondurensis Barret \& Golfari is highly important as a cultivated species for wooden production and approximately 1.8 million hectare are planted with the species, in Brazil. This research has aimed to verify through SSR markers the genetic variability in Pinus caribaea var. hondurensis, as well as its maintenance during genetic improvement, into the base population for breeding, a population of elite trees and an $F_{1}$ hybrid population. For this study we have transferred primers of SSR loci developed for other Pinus species. Eight out of 20 tested primers have been successfully transferred to the P. caribaea (RPS 25b, RPS 150, PSM 2, PR 4.6, PtTX 2037, PtTX 3029, RPTest 01, and RPTest 09). Inbreeding was verified within and between populations, and the highest observed value between populations was $\mathrm{F}_{\mathrm{ST}}=0.0213$. The observed heterozigosity $\left(\mathrm{H}_{\mathrm{o}}\right)$ and the expected heterozigosity $\left(\mathrm{H}_{\mathrm{e}}\right)$ means were, respectively, 0.2469 and 0.2489 . The highest genetic distance $(\mathrm{D}=0.0119)$ was observed between the base populations and the $\mathrm{F}_{1}$ improved population. Based on genetic distance values obtained for elite trees, 10 potential crossings between contrasting elite trees have been indicated, aiming to reach the hybrid vigor between progenies from those crossings.

Key words: Genetic markers, DNA, controlled pollinations, and genetic parameters.

$\left({ }^{1}\right)$ Recebido para publicação em 27 de março de 2006 e aceito em 4 de junho de 2007.

$\left({ }^{2}\right)$ Pós-Graduando do Departamento de Genética IB/UNESP- Caixa Postal 510, 18618-000 Botucatu (SP).

$\left({ }^{3}\right)$ Departamento de Produção Vegetal, FCA/UNESP, Caixa Postal 237, 18603-970 Botucatu (SP). E-mail: esmori@fca.unesp.br $\left(^{*}\right)$ Autor correspondente.

$\left({ }^{4}\right)$ Graduando de Engenharia Florestal, FCA/UNESP. E-mail: evtambarussi@fca.unesp.br; cbmoraes@fca.unesp.br

$\left({ }^{5}\right)$ Graduando de Engenharia Agronômica, FCA/UNESP, E-mail: fadjesus@fca.unesp.br

$\left({ }^{6}\right)$ Instituto Florestal, Caixa Postal 78, 18701-180 Avaré (SP). E-mail: nativas@fca.unesp.br. 


\section{INTRODUÇÃO}

As espécies do gênero Pinus foram introduzidas no Brasil na década de 1950, ocupando atualmente uma área que supera 1,8 milhões de hectares (Estatísticas, 2004). A introdução dessas espécies florestais no Brasil trouxe grandes benefícios para o desenvolvimento social e econômico do país, principalmente nas áreas em que as características edafoclimáticas eram desfavoráveis à agricultura. No Sudeste, as variedades da espécie Pinus caribaea têm destacada importância, predominando a área plantada com P. caribaea var. hondurensis Barret \& Golfari, nativo de países da América Central e México (Golfari, 1991).

Grande parte das áreas atualmente plantadas com Pinus caribaea var. hondurensis no Brasil tem origem, direta ou indireta, de uma única fonte de germoplasma de Agudos-SP. Neste local foram instalados pomares de sementes a partir de matrizes selecionadas em Poptun, localidade da Guatemala onde a variedade é nativa (BERTOLANI et al., 1984; Moura e DVOrak, 2001). Como o material genético inicialmente introduzido no Brasil foi submetido a sucessivas etapas de seleção por programas de melhoramento, sua variabilidade inicial pode ter sido bastante reduzida.

Os principais objetivos do melhoramento de espécies florestais são: o aumento da produtividade, a obtenção de matéria-prima de maior qualidade, a melhoria nas condições adaptativas das espécies, a tolerância a pragas e doenças e ainda a manutenção da variabilidade genética, requisito fundamental para a obtenção de ganhos genéticos em longo prazo (MoRI, 1993).

O uso da estaquia em Pinus vem se tornando comum em escala mundial. Várias espécies e híbridos estão sendo propagadas pela estaquia em níveis operacionais, em diversas partes do mundo: Nova Zelândia (Pinus radiata), Austrália ( $P$. radiata e $P$. caribaea x Pinus elliottii), Chile ( $P$. radiata e $P$. taeda), Venezuela (P. caribaea), África do Sul (Pinis patula e $P$. caribaea $\times$ P. elliottii) e Brasil ( $P$. taeda e $P$. caribaea $\mathrm{x}$ P. taeda) (Webere Stelzer, 2000). Ainda segundo Weber e Stelzer (2000), a propagação vegetativa pode gerar aumento de produtividade, maior uniformidade do produto final e rotações mais curtas, e grandes empresas do sudeste dos Estados Unidos estão no estágio inicial de desenvolvimento operacional de programas de enraizamento de estacas de Pinus.

A utilização de material juvenil é de fundamental importância para o sucesso do enraizamento (WENDLING e XAVIER, 2001). Quando se conhece o desempenho genético dos progenitores é possível multiplicar famílias inteiras, com a vantagem de dispensar testes de campo iniciais. A utilização de famílias, porém, resulta em uma maior desuniformidade do material, fato aceito pela dificuldade de obtenção de rejuvenescimento de material adulto em Pinus (Weber e Stelzer, 2000).

Atualmente, os marcadores moleculares são ferramentas importantes dentro de programas de melhoramento. Dentre eles, os microssatélites têm sido indicados para estudos de variabilidade genética, cálculos de freqüência alélica, desvio em relação ao equilíbrio de Hardy-Weinberg, mapeamento genético e físico de genomas, identificação e discriminação de genótipos, testes de paternidade e estudo de genética de populações, pois são de natureza co-dominante e constituem em uma das classes de marcadores moleculares mais polimórficas atualmente disponível (Ferreira e Gratapaglia, 1998).

Diante deste contexto, o presente trabalho teve como objetivo verificar, pela utilização de marcadores moleculares microssatélites (SSR "Simple Sequence Repeats"), a variabilidade genética em uma população-base de melhoramento de Pinus caribaea var. hondurensis, assim como sua manutenção durante o processo de melhoramento genético por seleção de matrizes e na primeira geração melhorada $F_{1}$.

\section{MATERIAL E MÉTODOS}

Foi utilizada uma população geneticamente variável de Pinus caribaea var. hondurensis, pertencente aos plantios da A. W. Faber-Castell S.A., na região de Prata (MG), com localização geográfica nas coordenadas $19^{\circ} 18^{\prime} 26^{\prime \prime} \mathrm{S}$ e $48^{\circ} 55^{\prime} 35^{\prime \prime} \mathrm{N}$, a uma altitude média de $630 \mathrm{~m}$, onde predomina o clima Tropical úmido (Classificação de Koppen) com estação seca durante o inverno. A média de temperatura é $22^{\circ} \mathrm{C}$, com precipitação pluvial média de $1.500 \mathrm{~mm}$ anuais.

A população-base foi formada a partir de sementes oriundas da Área de Produção de Sementes (APS) procedente de Agudos (SP). Nesta população, foram selecionadas árvores matrizes que formam Pomares de Sementes Clonais (PSC) e, dentre estas matrizes, realizados cruzamentos controlados.

Para avaliar a variabilidade genética da população-base, 80 árvores foram amostradas, ao acaso, em 650 ha. Na mesma área foram selecionadas 25 matrizes, obtidas por seleção massal, considerando as características volume de madeira e forma de fuste.

Para a população melhorada $\mathrm{F}_{1}$, dentre todos os cruzamentos realizados, foram selecionadas as oito 
progênies $\mathrm{F}_{1}$ superiores, de irmãos completos, obtidos por polinização controlada. Cada progênie foi representada por 10 plantas, totalizando 80 indivíduos obtidos nesta geração de seleção.

Acículas dessas plantas foram colhidas e seu DNA genômico foi extraído utilizando-se tampão de brometo de hexadeciltrimetilamônio (CTAB). Aproximadamente $0,5 \mathrm{~g}$ de tecido fresco foi triturado em moinho de maceração com $0,7 \mathrm{~mL}$ de tampão de extração (2\% CTAB;1,4 M NaCl; 20 mM EDTA pH 8,0; 100 mM Tris- $\mathrm{HCl}$ pH 8,0; 1 \% PVP 40; $2 \%$ mercaptoetanol) e incubado a $65^{\circ} \mathrm{C}$ por 40 minutos. $\mathrm{O}$ extrato obtido foi submetido a uma extração com clorofórmio-álcool isoamílico (24:1) e centrifugado, sendo o sobrenadante transferido para novos tubos. O DNA presente na fase aquosa foi precipitado adicionando-se ao sobrenadante $2 / 3$ do seu volume em isopropanol, incubando os tubos a $-20{ }^{\circ} \mathrm{C}$ por 40 minutos. O material foi novamente centrifugado, tornando os pellets de DNA visíveis, os quais foram submetidos a duas lavagens com álcool etílico $70 \%$, devidamente secos e ressuspendidos em $0,1 \mathrm{~mL}$ de tampão TE (10 mM Tris-Cl pH 8,0; 1 mM EDTA pH $8,0)$ contendo $10 \mathrm{mg} / \mathrm{mL}$ de RNAse.

O DNA extraído foi quantificado em espectrofotômetro do tipo GeneQuantPro e sua concentração, ajustada para $4 \mathrm{ng} / \mathrm{mL}$, para o uso na reação de polimerização em cadeia (PCR).

Para as amplificações utilizou-se o total de 20 pares de primers conforme a tabela 1 . As reações de amplificação foram realizadas em termociclador PTC - 100 (MJ Research Inc.), utilizando o seguinte perfil térmico: 5 minutos a $94{ }^{\circ} \mathrm{C}$, seguidos de 32 ciclos de 30 segundos a $94^{\circ} \mathrm{C}, 45$ segundos de anelamento com temperatura adequada aos primers utilizados e 1 minuto a $72{ }^{\circ} \mathrm{C}$, seguidos de 10 minutos a $72{ }^{\circ} \mathrm{C}$. O volume total da mistura foi de $17 \mathrm{~mL}$, contendo 1,7 mL de tampão 10 X PCR Buffer, 31 de DNA (4 ng/ $\mathrm{mL}), 0,3 \mathrm{~mL}$ de cada primer $(10 \mathrm{mM}), 1,5 \mathrm{~L}$ de solução de dNTP $(0,5 \mathrm{mM}), 0,1 \mathrm{~mL}(1 \mathrm{U})$ de Taq DNA Polymerase (Invitrogen Life Technologies) e 0,85 $\mu \mathrm{L}$ de $\mathrm{MgCl}_{2} 50 \mathrm{mM}$.

Obteve-se sucesso na transferência de 8 pares de primers, sendo 6 polimórficos: PSM 2 (com temperatura de anelamento a $56^{\circ} \mathrm{C} \mathrm{e} \mathrm{"touchdown"} \mathrm{de}$ $-0,2^{\circ} \mathrm{C} /$ ciclo $\times 32$ ciclos), PR $4.6\left(56^{\circ} \mathrm{C} \times 32\right.$ ciclos), PtTX $2037\left(50{ }^{\circ} \mathrm{C} \times 32\right.$ ciclos), PtTX $3029\left(60{ }^{\circ} \mathrm{C}-0,4\right.$ ${ }^{\circ} \mathrm{C} /$ ciclo x 32 ciclos), RPTest $01\left(60{ }^{\circ} \mathrm{C}-0,2{ }^{\circ} \mathrm{C} /\right.$ ciclo x 32 ciclos), RPTest $09\left(58{ }^{\circ} \mathrm{C}\right.$ x 15 ciclos iniciais +53 ${ }^{\circ} \mathrm{C}$ x 20 ciclos finais), e 2 monomórficos: RPS 25b (56 ${ }^{\circ} \mathrm{C}$ x 32 ciclos) e RPS $150\left(52^{\circ} \mathrm{C}\right.$ x 32 ciclos $)$.

Os produtos de amplificação foram submetidos à eletroforese em gel de agarose Metaphor (FMC Bioproducts) a 3\%; a coloração feita em banho de brometo de etídeo a $2 \%$ ( $2 \mathrm{~mL}$ em 1,5 $\mathrm{L}$ de água por 1 hora). As bandas foram visualizadas em luz ultravioleta e fotografadas. A interpretação das bandas nos géis foi feita visualmente e a definição da variação do tamanho dos fragmentos realizada com o programa EagleSight versão 3.21 (Stratagene).

Procurou-se atribuir aos alelos, números relativos à sua freqüência. Desta forma, o alelo mais freqüente de cada loco foi denominado de alelo 1 , o segundo mais freqüente foi chamado de alelo $2 \mathrm{e}$ assim sucessivamente. Os parâmetros genéticos foram calculados pelo programa computacional Tools for Population Genetic Analyses TFPGA versão 1.3 (Miller, 1997), através dos procedimentos descritos a seguir.

\section{Freqüências alélicas}

As freqüências dos alelos foram obtidas contando-se diretamente o número de alelos por loco e dividindo-os pelo número total de alelos no loco. As freqüências alélicas esperadas foram estimadas a partir das freqüências observadas, obedecendo-se o equilíbrio de Hardy- Weinberg. O número médio de alelos por loco foi estimado pela média aritmética dos locos estudados.

\section{Heterozigose}

a. Heterozigosidade observada $\left(\mathrm{H}_{\mathrm{o}}\right)$

A quantidade de heterozigose de um determinado loco seguiu os procedimentos de BROWN e WEIR (1983):

$$
\mathrm{H}_{\mathrm{o}}=1-\sum \mathrm{Pii} \text {; }
$$

Sendo: Pii - a freqüência observada de genótipos homozigotos do alelo i.

A heterozigosidade média observada foi obtida pela soma dos valores de cada loco dividindose pelo número total de locos estudados.

b. Heterozigosidade estimada $\left(\hat{H}_{e}\right)$

A quantidade de heterozigose estimada teve como base NEI (1978):

$$
\hat{H}_{e}=1-\sum P_{i}^{2} \text {; }
$$

alelo.

sendo $\mathrm{P}_{i}$ - a freqüência estimada do iésimo

A heterozigosidade média esperada foi obtida pela média aritmética de todos os locos estudados.

c. Percentagem de locos polimórficos $(\hat{P})$ 
Tabela 1. Nome dos locos microssatélites, espécie para a qual foram desenhados, seqüência de nucleotídeos dos primers forward $(\mathrm{F})$ e reverse $(\mathrm{R})$ e referência bibliográfica

\begin{tabular}{|c|c|c|c|c|}
\hline Loco & Espécie & Motif & Seqüência & Referência \\
\hline RPS 12 & P. strobus & $(\mathrm{AC})$ & $\begin{array}{l}\text { F: TCA ATG TGG AGA TGG TGA TT } \\
\text { R: ACT TCT GAC CTA ACC AGA AAC C }\end{array}$ & EсHT et al. 1996 \\
\hline RPS 20 & P. strobus & $(\mathrm{AC})(\mathrm{AT})$ & $\begin{array}{l}\text { F: ACT TCC CCA CAG GTT AAC ACA } \\
\text { R: AAC AAG ATA GGC GGG ATT CA }\end{array}$ & Еснт et al. 1996 \\
\hline RPS 25b & P. strobus & $(\mathrm{AC})(\mathrm{AT})$ & $\begin{array}{l}\text { F: CAC ATA TGG CAG AAC ACA CA } \\
\text { R: GAT CGT CGC ACT GAA C }\end{array}$ & EсHT et al. 1996 \\
\hline RPS 84 & P. strobus & $(\mathrm{AG})(\mathrm{AC})$ & $\begin{array}{l}\text { F: CCT TTG GTC ATT GTA TTT TTG GAC } \\
\text { R: CTT CCT TTT CCT TCT TGC TCC AC }\end{array}$ & EсHT et al. 1996 \\
\hline PMS 2 & P. sylvestris & $(\mathrm{AC})_{8}$ & $\begin{array}{l}\text { F: GGG TGA ATG GCC CAA TAG TA } \\
\text { R: GTA GTG TCC CCT CAC ATG CA }\end{array}$ & Kostia et al. 1995 \\
\hline PMS 4 & P. sylvestris & $(\mathrm{GT})_{9}(\mathrm{~N})_{21}(\mathrm{AT})_{24}$ & $\begin{array}{l}\text { F: TTC ACT AGG CCA AAT GCA CT } \\
\text { R: TGC CTA TGC AAA GAG ACT CA }\end{array}$ & Kostia et al. 1995 \\
\hline PR 4.6 & P. radiata & $(\mathrm{AC})$ & $\begin{array}{l}\text { F: GAA AAA AAG GCA AAA AAA AGG AG } \\
\text { R: ACC CAA GGC TAC ATA ACT CG }\end{array}$ & Smith e Dever 1994 \\
\hline PR 9.3 & P. radiata & $(\mathrm{AC})$ & $\begin{array}{l}\text { F: GAA ATT TAA CAC CAC ACC GTT G } \\
\text { R: TGG GGC TTA AAG TGA AAT GG }\end{array}$ & Smith e Devey 1994 \\
\hline APC 3 & $\begin{array}{l}\text { P. contorta } \\
\text { var. latifolia }\end{array}$ & $(\mathrm{GA})_{33}$ & $\begin{array}{l}\text { F: AGT GCT TCA AGA AAA TCT AAG T } \\
\text { R: TTG TAA CCT TTT ATG AGT TCA G }\end{array}$ & Нiскs et al. 1998 \\
\hline APC 9 & $\begin{array}{l}\text { P. contorta } \\
\text { var. latifolia }\end{array}$ & $(\mathrm{TA})_{16}(\mathrm{GA})_{21}$ & $\begin{array}{l}\text { F: TGA ATG AGA AGT CGT GTA AG } \\
\text { R: GGA ATA AGA CAG GTT CAG AT }\end{array}$ & Нiскs et al. 1998 \\
\hline APC 11 & $\begin{array}{l}\text { P. contorta } \\
\text { var. latifolia }\end{array}$ & $(\mathrm{AT})_{10}(\mathrm{AG})_{21}$ & $\begin{array}{l}\text { F: TCC CTT TAG ATA GTT CAT GG } \\
\text { R: GAT ATT GTC TTC GCT GAT AG }\end{array}$ & Hicks et al. 1998 \\
\hline APC 13 & $\begin{array}{l}\text { P. contorta } \\
\text { var. latifolia }\end{array}$ & $(\mathrm{AG})_{29}$ & $\begin{array}{l}\text { F: TCA AGC CTA GTC AGT GTT AAG } \\
\text { R: CCA AGA AAA CTC TAA GTG AGC }\end{array}$ & НiскS et al. 1998 \\
\hline RPS 150 & P. strobus & (GAG) & $\begin{array}{l}\text { F: TCC ATC AGT GAG CAG TGG } \\
\text { R: CAC TTG GGC TTC CTC TTC }\end{array}$ & EсHT et al. 1996 \\
\hline RPS 160 & P. strobus & (ACAG) & $\begin{array}{l}\text { F: ACT AAG AAC TCT CCC TCT CAC C } \\
\text { R: TCA TTG TTC CCC AAA TCA T }\end{array}$ & Еснт et al. 1996 \\
\hline PtTX 2037 & P. taeda & $(\mathrm{GTGA})_{8}(\mathrm{GT})_{14}$ & $\begin{array}{l}\text { F: GCC TTT AGA TGA ATG AAC CAA } \\
\text { R: TAA GCG GGA TAT TAT AGA GTT T }\end{array}$ & ELsIK et al. 2000 \\
\hline PtTX 2034 & P. taeda & $(\mathrm{TTTG})_{9}$ & $\begin{array}{l}\text { F: TCT GAG GAG GAA CAT GTC ATT TAC T } \\
\text { R: GCA TGT CTG AAT TAT TGT GTT CTA T }\end{array}$ & ELsIK et al. 2000 \\
\hline PtTX 3011 & P. taeda & $(\mathrm{GAA})_{8}(\mathrm{GAT})_{18}$ & $\begin{array}{l}\text { F: AAT TTG GGT GTA TTT TTC TTA GA } \\
\text { R: AAA AGT TGA AGG AGT TGG TGA TC }\end{array}$ & ELSIK et al. 2000 \\
\hline PtTX 3029 & P. taeda & $\begin{array}{l}(\mathrm{GCT})_{5} \ldots(\mathrm{GCT})_{8} \\
\ldots(\mathrm{GCT})_{5}\end{array}$ & $\begin{array}{l}\text { F: CTT GTT GCT GCT TCT GC } \\
\text { R: AAC AAA ATA ATA TAA ATG CTC TGC }\end{array}$ & ELSIK et al. 2000 \\
\hline RPTest 01 & P. taeda & $(\mathrm{ATA})_{7}$ & $\begin{array}{l}\text { F: GAT CGT TAT TCC TCC TGC CA } \\
\text { R: TTC GAT ATC CTC CCT GCT TG }\end{array}$ & ECHT e BuRns 1999 \\
\hline RPTest 09 & P. taeda & $\begin{array}{l}(\mathrm{A}) 5(\mathrm{TG})_{4}(\mathrm{GAG})_{5} \\
(\mathrm{CAG})_{11}(\mathrm{GCA})_{7} \\
(\mathrm{GCA})_{5}\end{array}$ & $\begin{array}{l}\text { F: CCA GAC AAC CCA AAT GAA GG } \\
\text { R: GCC TGC TAT CGA ATC CAG AA }\end{array}$ & ECHT e BURns 1999 \\
\hline
\end{tabular}


Para se estimar o polimorfismo de um determinado loco, considerou-se como tal, aquele cuja freqüência do alelo mais comum não ultrapassasse a $0,95(95 \%)$ e 0,99 (99\%).

\section{d. Índice de fixação de Wright $(\hat{F})$}

O índice de fixação de Wright (1965) ou o coeficiente de endogamia foi estimado com base na heterozigosidade observada $\left(\mathrm{H}_{\mathrm{o}}\right)$ e esperada $\left(\hat{H}_{e}\right)$. A fórmula utilizada foi:

$$
\hat{F}_{I S}=1-\frac{\mathrm{H}_{\mathrm{o}}}{\hat{H}_{e}}
$$

\section{Distância e identidade genética}

a. Distância genética $(\hat{D})$

A distância genética entre duas populações foi estimada segundo NEI (1972):

$\hat{D}=\ln \hat{I} ;$

sendo $(\hat{I})$ - o índice de identidade genética.

b. Índice de identidade genética $(\hat{I})$

Índice de identidade genética $(\hat{I})$, segundo NEI (1972), baseia-se em freqüências alélicas de locos homólogos nas diferentes populações. A expressão é a seguinte:

$$
\hat{I}=\frac{J_{x y}}{\sqrt{J_{x}-J_{y}}} ;
$$

sendo:

$\mathrm{J}_{\mathrm{xy}}, \mathrm{J}_{\mathrm{x}}$ e $\mathrm{J}_{\mathrm{y}}$, respectivamente, as médias aritméticas de $j_{x y}, j_{x}$ e $j_{y}$ sobre todos os locos polimórficos e monomórficos.

Para compreensão da expressão:

$\mathrm{j}_{\mathrm{xy}}=\sum x_{i}^{2}$ é a probabilidade de 2 genes escolhidos ao acaso na população $\mathrm{x}$ serem idênticos;

$\mathrm{j}_{\mathrm{x}}=\sum y^{2}$ é a probabilidade de 2 genes escolhidos ao acáso na população y serem idênticos;

$\mathrm{j}_{\mathrm{y}}=\sum \mathrm{x}_{\mathrm{i}} \mathrm{y}_{\mathrm{i}}$ é a probabilidade de identidade de um gene da população $x$ e um gene da população y serem idênticos.

\section{c. Estatística F}

A expressão de WRIGHT (1965) para medir a diversidade genética é a seguinte:

$$
\begin{aligned}
& \left(1-\hat{F}_{I T}\right)=\left(1-\hat{F}_{I S}\right)\left(1-\hat{F}_{S T}\right) \text { ou } \\
& \hat{F}_{I T}=\hat{F}_{S T}+\left(1-\hat{F}_{S T}\right) \cdot \hat{F}_{I S} ; \\
& \text { sendo: }
\end{aligned}
$$

$\hat{F}_{I T}$ - índice de fixação para a população, ou seja, é a probabilidade total de identidade num determinado indivíduo I;
$\hat{F}_{I S}$ - índice de fixação que ocorre dentro de populaçẫo, ou seja, é a probabilidade de que 2 genes sejam homólogos no indivíduo I derivado do mesmo gene de um ancestral comum dentro da população;

$\hat{F}_{S T}$ - índice de fixação para alelos por locos, ou seja, é a probabilidade de que 2 genes sejam homólogos, combinados ao acaso na população, ambos originários de um gene na população.

\section{RESULTADOS E DISCUSSÃO}

Neste estudo foram avaliados 20 locos utilizando primers desenvolvidos para outras espécies de Pinus (Tabela 1). Desses foram amplificados oito locos, com polimorfismo nos locos PSM 2, PR 4.6, PtTX 2037, PtTX 3029, RPTest 01 e RPTest 09, enquanto os locos RPS 25b e RPS 150 foram monomórficos. 2002 SHEPHERD et al. $(2002,2003)$ também obtiveram transferência de primers de outras espécies de Pinus para o P. caribaea, onde PR 4.6, PtTX 2037, PtTX 3029, RPTest 01 e RPTest 09 aqui estudados são os mesmos amplificados nestes trabalhos. Entretanto PR 9.3, PtTX2034 e PtTX3011 que também foram testados, não amplificaram fragmentos nestas populações.

As freqüências alélicas foram determinadas para cada loco polimórfico na população-base, nas matrizes selecionadas e na geração de seleção $F_{1}$ (Tabela 2). Na população base a freqüência dos alelos mais comuns variou entre 0,5270 (alelo 1 do PtTX 3029) e 0,9508 (alelo 1 do PtTX 2037) e para os alelos de menor freqüência a variação ficou entre 0,0492 e 0,1554 (alelo 2 do PtTX 2037 e alelo 3 do PtTX 3029 respectivamente).

Entre as matrizes essa variação foi de 0,5263 (alelo 1 do PtTX 3029) a 0,9762 (alelo 1 do RPTest 01) para os alelos de maior freqüência, e de 0,0238 (alelo 3 do RPTest 01) a 0,1892 (alelo 3 do RPTest 09) para os alelos de menor freqüência.

Finalmente, para a população melhorada $\mathrm{F}_{1}$ a variação foi de 0,6083 (alelo 1 do PR 4.6) a 1 para o alelo 1 do RPTest 01, para os alelos de maior freqüência. Para os alelos de menor freqüência a variação foi de 0,3904 (alelo 2 do PtTX 3029) a 0,0278 (alelo 3 do RPTest 09).

A tabela 2 mostra também que ocorreu a perda de alelos durante o processo de seleção, o alelo 2 do loco RPTest 01 não foi identificado entre as matrizes estudadas e na população $F_{1}$ houve a fixação do alelo 1 para este mesmo loco, como resultado da perda dos alelos 2 e 3 . Foram ainda perdidos na mesma população, o alelo 3 do loco PtTX 3029 e o alelo 4 do loco PR 4.6. 
Tabela 2. Freqüências alélicas de cada loco estudado, determinadas na população base, árvores matrizes selecionadas e população melhorada $F_{1}$

\begin{tabular}{lcccc}
\hline Loco & Alelo & População base & Matrizes selecionadas & População Melhorada $\mathrm{F}_{1}$ \\
\hline PtTX & 1 & 0,9508 & 0,8958 & 0,9177 \\
2037 & 2 & 0,0492 & 0,1042 & 0,0823 \\
PtTX & 1 & 0,5270 & 0,5652 & 0,6096 \\
3029 & 2 & 0,3176 & 0,3478 & 0,3904 \\
& 3 & 0,1554 & 0,0870 & $0,0000^{*}$ \\
RPTest & 1 & 0,8974 & 0,9762 & 1,0000 \\
01 & 2 & 0,0385 & $0,0000^{*}$ & $0,0000^{*}$ \\
& 3 & 0,0641 & 0,0238 & $0,0000^{*}$ \\
RPTest & 1 & 0,6831 & 0,5263 & 0,6319 \\
09 & 2 & 0,2254 & 0,2895 & 0,3403 \\
PR 4.6 & 3 & 0,0915 & 0,1892 & 0,0278 \\
& 1 & 0,7308 & 0,5909 & 0,6083 \\
PSM 2 & 2 & 0,1000 & 0,2273 & 0,1167 \\
& 3 & 0,0923 & 0,1364 & 0,2750 \\
& 4 & 0,0769 & 0,0455 & $0,0000^{*}$ \\
\end{tabular}

* Alelos perdidos durante processo de seleção.

Deve-se ressaltar que o número de matrizes estudadas é inferior ao existente no Pomar de Sementes Clonal (PSC) implantado para o desenvolvimento do programa de seleção recorrente, e que a variabilidade na geração $F_{1}$ foi avaliada em progênies de irmãos completos. Esses fatores contribuem para a redução da variabilidade verificada em $\mathrm{F}_{1} \mathrm{e}$, possivelmente, a tornam mais acentuada do que ela realmente seria em um PSC de base genética ampla, cujos cruzamentos ocorrem de forma aberta. Verifica-se claramente que a pressão de seleção em um número pequeno de indivíduos avaliados, provoca a perda de alelos.

A perda de alelos isoenzimáticos foi verificada por MORI (1993) em estudo semelhante, realizado com pomares de sementes de Eucalyptus grandis de bases genéticas diferentes: grande, intermediária e pequena. Houve a perda de sete alelos isoenzimáticos, de um total de 21, quando a base genética foi reduzida de grande para intermediária e 10 alelos quando esta base se tornou pequena.

HAMrick (1991), estudando a manutenção da diversidade genética em Pinus taeda, fez comparações entre dois pomares de sementes com 16 populações naturais da espécie. Dos 69 alelos isoenzimáticos observados nas populações naturais, somente $62,3 \%$ e $60,9 \%$ foram mantidos em cada um dos pomares; dos alelos erodidos todos tinham freqüências gênicas inferiores a $10 \%$ e a maioria dos alelos ausentes nos pomares (cerca de $65 \%$ ) tinham freqüências abaixo de $1 \%$. O monitoramento do processo de erosão genética é uma ferramenta imprescindível para que o melhorista possa intervir quando necessário (Mori, 1993; Williams e Hamrick, 1995).

A variabilidade genética também foi demonstrada por estimativa de heterozigosidade, locos polimórficos, tamanho da amostra e número de alelos por loco, para ambas as etapas do programa de melhoramento. Esses parâmetros foram calculados para os seis locos polimórficos e para os dois locos monomórficos.

Os tamanhos da amostra média por loco foram 73,$50 ; 22,75$ e 74,75 , para a população base, matrizes selecionadas e população melhorada $F_{1}$ respectivamente. Essa variação se deve à diferença no número de indivíduos amostrados em cada etapa do programa de melhoramento. O número médio de alelos por loco decresceu no decorrer de cada etapa de melhoramento, passando de 2,375 na população-base, para 2,250 nas matrizes selecionadas e 1,875 na população melhorada $F_{1}$. Esses valores são resultantes da perda de alelos ocasionada pela seleção. 
As percentagens de locos polimórficos foram calculadas a $95 \%$ e $99 \%$, ou seja, quando o alelo mais freqüente não atingir valores superiores a 0,95 e 0,99, respectivamente. A $95 \%$, a proporção de locos polimórficos foi de $62,5 \%$ para as três populações. Enquanto a $99 \%$ um total de $75 \%$ dos locos foram polimórficos para a população-base e matrizes selecionadas e $62,5 \%$ para a geração melhorada $F_{1}$. É importante ressaltar mais uma vez, que para o cálculo das porcentagens dos locos polimórficos, foram considerados os locos monomórficos RPS 25b e RPS 150.

As heterozigosidades médias observadas e esperadas foram respectivamente 0,2469 e 0,2489 para a população-base, 0,3087 e 0,2676 para as matrizes selecionadas e 0,2377 e 0,2455 na geração $F_{1}$. O maior desvio entre valores de heterozigosidade observados e esperados foi verificado para as matrizes selecionadas, e aparentemente este desvio está relacionado ao número pequeno de matrizes amostradas, em relação as amostras da população base e $\mathrm{F}_{1}$. $\mathrm{O}$ número de amostras também é reduzido em $\mathrm{F}_{1}$, o que pode estar acontecendo é que nas progênies o efeito heterótico selecionado nas matrizes diminuiu com a segregação nas progênies. O indice de endogamia $f$ é maior na população base $(0,008)$ em relação às matrizes $(-0,154)$ e geração $F_{1}(-0,032)$. A seleção pode ter influenciado a escolha de indivíduos com mais quantidade de heterozigose.

Na tabela 3, está apresentado o resultado do teste qui-quadrado $\left(\dot{\leftarrow}^{2}\right)$ para o Equilíbrio de HardyWeinberg (EHW). Nela verificam-se os números de genótipos observados e esperados, os valores de $\div^{2} \mathrm{e}$ a probabilidade (p) dos locos polimórficos estarem em EHW, para população base, matrizes e população melhorada $\mathrm{F}_{1}$. Observamos que ocorreu desequilíbrio no loco PtTX 2037 na população base, no loco PtTX 3029 nas matrizes selecionadas e no loco PSM 2 da geração $\mathrm{F}_{1}$. $\mathrm{O}$ desequilíbrio ocorreu em apenas um loco por população e não no mesmo loco, menos do que era esperado de acordo com os fatores evolutivos descritos em Grifriths et. al. (2002), onde a seleção é um dos fatores que afetam o equilíbrio das freqüências alélicas como também os cruzamentos controlados que alteraram o sistema reprodutivo.

Tabela 3. Teste qui-quadrado $\left(\chi^{2}\right)$ para o Equilíbrio de Hardy-Weinberg (EHW) dos locos polimórficos, para populaçãobase, matrizes e população melhorada $\mathrm{F}_{1}$

\begin{tabular}{|c|c|c|c|c|c|c|c|c|c|c|}
\hline \multirow[b]{2}{*}{ Loco } & \multirow[b]{2}{*}{ Tipo (a) } & \multicolumn{3}{|c|}{ População base } & \multicolumn{3}{|c|}{ Matrizes selecionadas } & \multicolumn{3}{|c|}{ População melhorada } \\
\hline & & $\mathrm{N}^{\mathrm{o}}$ obs. & $\begin{array}{c}\mathrm{N}^{\mathrm{o}} \\
\text { esperado }\end{array}$ & $\begin{array}{l}\chi^{2} \\
(p)\end{array}$ & N. ${ }^{\circ}$ obs. & $\begin{array}{c}\mathrm{N}^{\mathrm{o}} \\
\text { esperado }\end{array}$ & $\begin{array}{l}\chi^{2} \\
(p)\end{array}$ & $\mathrm{N}^{\mathrm{o}}$ obs. & $\begin{array}{c}\mathrm{N}^{\mathrm{o}} \\
\text { sperado }\end{array}$ & $\begin{array}{l}\chi^{2} \\
(p)\end{array}$ \\
\hline \multirow[t]{3}{*}{ PtTX 2037} & 11 & 56 & 55,15 & 5,45 & 20 & 19,26 & 2,62 & 67 & 66,53 & 0,48 \\
\hline & $1^{*}$ & 4 & 5,7 & $-0,02$ & 3 & 4,48 & $-0,106$ & 11 & 11,93 & $-0,488$ \\
\hline & ** & 1 & 0,15 & & 1 & 0,26 & & 1 & 0,53 & \\
\hline \multirow[t]{3}{*}{ PtTX 3029} & 11 & 17 & 20,55 & 2,75 & 5 & 7,35 & 3,97 & 24 & 27,13 & 2,36 \\
\hline & $1^{*}$ & 44 & 36,89 & $-0,097$ & 16 & 11,3 & $-0,046$ & 41 & 34,75 & $-0,124$ \\
\hline & $* *$ & 13 & 16,55 & & 2 & 4,35 & & 8 & 11,13 & \\
\hline \multirow[t]{3}{*}{ RPTest 01} & 11 & 62 & 62,82 & 1,02 & 20 & 20,01 & 0,91 & 80 & 80 & (b) \\
\hline & $1^{*}$ & 16 & 14,35 & $-0,313$ & 1 & 0,98 & $-0,911$ & 0 & 0 & \\
\hline & ** & 0 & 0,82 & & 0 & 0,01 & & 0 & 0 & \\
\hline \multirow[t]{3}{*}{ RPTest 09} & 11 & 34 & 33,13 & 0,23 & 4 & 5,26 & 1,35 & 28 & 28,75 & 0,15 \\
\hline & $1^{*}$ & 29 & 30,74 & $-0,634$ & 12 & 9,47 & $-0,245$ & 35 & 33,49 & $-0,703$ \\
\hline & $* *$ & 8 & 7,13 & & 3 & 4,26 & & 9 & 9,75 & \\
\hline \multirow[t]{3}{*}{ PR 4.6} & 11 & 37 & 34,71 & 2,08 & 7 & 7,68 & 0,36 & 28 & 22,2 & 9,86 \\
\hline & $1^{*}$ & 21 & 25,58 & $-0,149$ & 12 & 10,64 & $-0,548$ & 17 & 28,59 & $-0,002$ \\
\hline & ** & 7 & 4,71 & & 3 & 3,68 & & 15 & 9,2 & \\
\hline \multirow[t]{3}{*}{ PSM 2} & 11 & 64 & 63,81 & 0,06 & 20 & 20,1 & 0,11 & 50 & 49,46 & 0,18 \\
\hline & $1^{*}$ & 14 & 14,38 & $-0,814$ & 3 & 2,8 & $-0,738$ & 21 & 22,07 & $-0,676$ \\
\hline & $* *$ & 1 & 0,81 & & 0 & 0,1 & & 3 & 2,46 & \\
\hline
\end{tabular}

(a) 11 - número de homozigotos para o alelo mais comum.

$1^{*}$ - número de heterozigotos compostos pelos alelos mais comuns e o raro;

** - número de homozigotos para o alelo raro e outros heterozigotos.

(b) Não é possível calcular o EHW, pois existe apenas um alelo. 
Desvios da estrutura genética das outras populações em relação à população base também foram confirmados na tabela 4 , os quais possivelmente estão ligados à endogamia gerada pela seleção, em que são mostrados os índices de fixação da estatística $F$ de Wright, para os alelos polimórficos de todos os indivíduos amostrados. Pelos índices nota-se que existe endogamia quando analisadas em conjunto com a população-base, as matrizes selecionadas e a população melhorada $F_{1}$. Da endogamia total, o maior valor encontrado foi entre populações $\mathrm{F}_{\mathrm{ST}}=0,0213$.
Há também uma heterozigosidade observada maior que a esperada $F_{I S}=-0,0061$, principalmente nas matrizes selecionadas onde deve existir grande efeito heterótico da seleção massal de 25 indivíduos em 650 ha, que é dissipado por segregação nos cruzamentos da geração $F_{1}$. Distâncias genéticas de NeI (1972) entre população-base com matrizes $(0,0084)$ e matrizes com geração $\mathrm{F}_{1}(0,0094)$ não foram elevadas. A maior distância foi observada entre população-base e geração $F_{1}(0,0119)$, em função do acúmulo do efeito de dois ciclos de seleção.

Tabela 4. Índices de fixação dentro $\left(\mathrm{F}_{\mathrm{IS}}\right)$, entre as populações $\left(\mathrm{F}_{\mathrm{ST}}\right)$ e total $\left(\mathrm{F}_{\mathrm{IT}}\right)$, para todos os alelos polimórficos e indivíduos da população-base, das matrizes selecionadas e da população melhorada $\mathrm{F}_{1}$

\begin{tabular}{|c|c|c|c|c|c|c|}
\hline \multirow{2}{*}{ Loco } & \multirow{2}{*}{$\mathrm{F}$} & \multicolumn{4}{|c|}{ Alelo } & \multirow{2}{*}{ Média } \\
\hline & & 1 & 2 & 3 & 4 & \\
\hline \multirow[t]{3}{*}{ PtTX 2037} & $\mathrm{~F}_{\mathrm{IT}}$ & 0,1930 & 0,1930 & - & - & 0,1930 \\
\hline & $\mathrm{F}_{\mathrm{ST}}$ & $-0,0025$ & $-0,0025$ & - & - & $-0,0025$ \\
\hline & $\mathrm{F}_{\mathrm{IS}}$ & 0,1949 & 0,1949 & - & - & 0,1949 \\
\hline \multirow[t]{3}{*}{ PtTX 3029} & $\mathrm{~F}_{\mathrm{IT}}$ & $-0,2065$ & $-0,1048$ & 0,1148 & - & $-0,1198$ \\
\hline & $\mathrm{F}_{\mathrm{ST}}$ & 0,0022 & $-0,0004$ & 0,1038 & - & 0,0152 \\
\hline & $\mathrm{F}_{\mathrm{IS}}$ & $-0,2092$ & $-0,1044$ & 0,0123 & - & $-0,1371$ \\
\hline \multirow[t]{3}{*}{ RPTest 01} & $\mathrm{~F}_{\mathrm{IT}}$ & $-0,0144$ & $-0,0030$ & $-0,0117$ & - & $-0,0115$ \\
\hline & $\mathrm{F}_{\mathrm{ST}}$ & 0,0780 & 0,0277 & 0,0419 & - & 0,0574 \\
\hline & $\mathrm{F}_{\mathrm{IS}}$ & $-0,1002$ & $-0,0316$ & $-0,0559$ & - & $-0,0730$ \\
\hline \multirow[t]{3}{*}{ RPTest 09} & $\mathrm{~F}_{\mathrm{IT}}$ & $-0,0146$ & $-0,0534$ & $-0,0549$ & - & $-0,0359$ \\
\hline & $\mathrm{F}_{\mathrm{ST}}$ & 0,0070 & 0,0144 & 0,0512 & - & 0,0161 \\
\hline & $\mathrm{F}_{\mathrm{IS}}$ & $-0,0218$ & $-0,0688$ & $-0,1118$ & - & $-0,0529$ \\
\hline \multirow[t]{3}{*}{ PR 4.6} & $\mathrm{~F}_{\mathrm{IT}}$ & 0,2499 & $-0,0716$ & 0,1947 & $-0,0228$ & 0,1457 \\
\hline & $\mathrm{F}_{\mathrm{ST}}$ & 0,0153 & 0,0175 & 0,0688 & 0,0414 & 0,0328 \\
\hline & $\mathrm{F}_{\mathrm{IS}}$ & 0,2382 & $-0,0906$ & 0,1351 & $-0,0670$ & 0,1167 \\
\hline \multirow[t]{3}{*}{ PSM 2} & $\mathrm{~F}_{\mathrm{IT}}$ & 0,0601 & 0,0601 & - & - & 0,0601 \\
\hline & $\mathrm{F}_{\mathrm{ST}}$ & 0,0203 & 0,0203 & - & - & 0,0203 \\
\hline & $\mathrm{F}_{\mathrm{IS}}$ & 0,0406 & 0,0406 & - & - & 0,0406 \\
\hline \multirow[t]{3}{*}{ MÉDIA } & $\mathrm{F}_{\mathrm{IT}}$ & - & - & - & - & 0,0153 \\
\hline & $\mathrm{F}_{\mathrm{ST}}$ & - & - & - & - & 0,0213 \\
\hline & $\mathrm{F}_{\mathrm{IS}}$ & - & - & - & - & $-0,0061$ \\
\hline
\end{tabular}

\section{Distância Genética entre Matrizes}

A partir dos dados obtidos para as árvores matrizes analisadas é possível sugerir a realização de cruzamentos ou acompanhar possíveis cruzamentos potenciais, com base nas distâncias genéticas entre matrizes, a fim de explorar o vigor híbrido das progênies. Partindo do pressuposto que a união de genótipos contrastantes pode levar ao vigor híbrido, foram calculadas as distâncias genéticas de NeI (1972) entre as matrizes estudadas. A maior distância ficou entre as matrizes 13 e $16(0,5825)$, seguido das distâncias da matriz 7 com 16 (0,4375), 15 com $16(0,4167), 2$ com 15 $(0,4167), 13$ com $19(0,3750), 13$ com $14(0,3750), 2$ com $13(0,3750), 2$ com $7(0,3750), 9$ com $13(0,3500)$ e 6 com $13(0,3500)$. Assim as matrizes $2,7,13,15$ e 16 não possuem parentesco elevado com as outras matrizes do ensaio (Figura 1), as matrizes 2 e 16 podem ter algum parentesco (agrupamento A) enquanto 7,13 e 15 são muito distantes destas, entre si e das outras matrizes, portanto recomendadas para cruzamentos similares aos realizados para aumentar a diversidade de cruzamentos em soja (Ferreira e Grattapaglia, 1998) e eucalipto (RochA et al., 2002). 


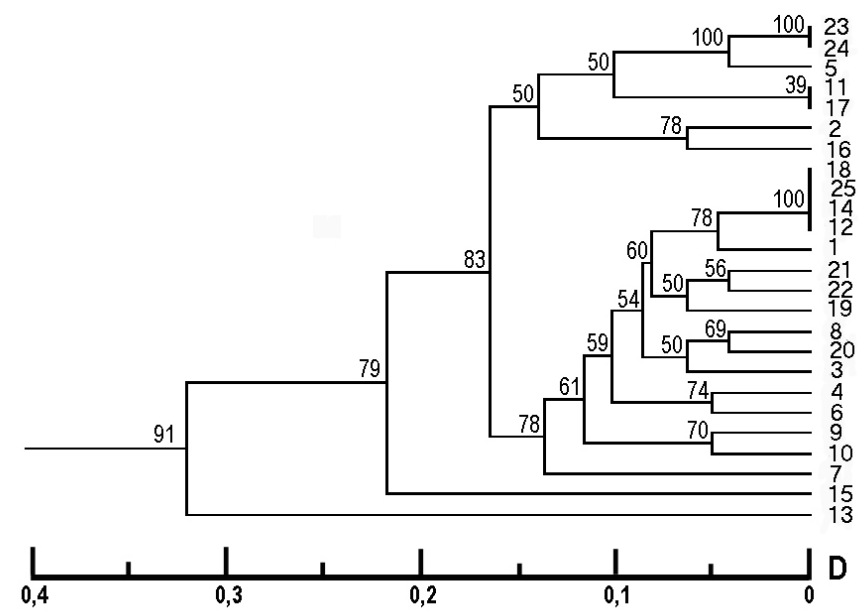

Figura 1. Dendrograma com base na distância genética de Nei (1972) entre matrizes (D), construído pelo método de UPGMA (Unweighted Pair-Group Method using Arithmetic averages) com consistência dos nós em porcentagem de reamostragens semelhantes.

Ocorreram também outros agrupamentos menos distantes entre si como B $(1,18,25,14 \mathrm{e} 12), \mathrm{C}$ (23 com 24), D (11e 17; 19), E (21 com 22), F (3, 8 e
20), G (4 com 6) e H (9 com 10) observados na figura 1 , provavelmente matrizes com certo grau de parentesco, devendo ser evitado o cruzamento entre matrizes dentro dos grupos.

\section{Diversidade Genética entre Progênies}

Mudas das progênies de irmãos completos, utilizadas no estudo da população melhorada $\mathrm{F}_{1}$, foram obtidas com objetivo de serem propagadas pelo processo vegetativo de estaquia. Com o intuito de verificar a variabilidade dessas progênies foram calculados os parâmetros da estatística F de Wright, para todos os alelos polimórficos das progênies, conforme mostra a tabela 5 .

Os resultados mostraram que o maior valor de diversidade genética foi observado entre as progênies $\left(\mathrm{F}_{\mathrm{ST}}=0,0901\right)$. Esse resultado é extremamente interessante do ponto de vista produtivo, pois a partir dele espera-se obter progênies homogêneas em relação às características de produtividade e qualidade. Ao mesmo tempo, espera-se uma diversidade entre as progênies, de forma que as melhores possam ser selecionadas para produtividade e qualidade do produto final e clonadas.

Tabela 5. Variabilidade genética dentro $\left(\mathrm{F}_{\mathrm{IS}}\right)$, entre as progênies $\left(\mathrm{F}_{\mathrm{ST}}\right)$ e total $\left(\mathrm{F}_{\mathrm{IT}}\right)$, para todos os alelos polimórficos da população melhorada $\mathrm{F}_{1}$

\begin{tabular}{|c|c|c|c|c|c|}
\hline \multirow{2}{*}{ Loco } & \multirow{2}{*}{$\mathrm{F}$} & \multicolumn{3}{|c|}{ Alelo } & \multirow{2}{*}{ Média } \\
\hline & & 1 & 2 & 3 & \\
\hline \multirow[t]{3}{*}{ PtTX 2037} & $\mathrm{~F}_{\mathrm{IT}}$ & 0,1175 & 0,1175 & - & 0,1175 \\
\hline & $\mathrm{F}_{\mathrm{ST}}$ & 0,3177 & 0,3177 & - & 0,3177 \\
\hline & $\mathrm{F}_{\mathrm{IS}}$ & $-0,2935$ & $-0,2935$ & - & $-0,2935$ \\
\hline \multirow[t]{3}{*}{ PtTX 3029} & $\mathrm{~F}_{\mathrm{IT}}$ & $-0,1698$ & $-0,1698$ & - & $-0,1698$ \\
\hline & $\mathrm{F}_{\mathrm{ST}}$ & 0,0260 & 0,0260 & - & 0,0260 \\
\hline & $\mathrm{F}_{\mathrm{IS}}$ & $-0,2010$ & $-0,2010$ & - & $-0,2010$ \\
\hline \multirow[t]{3}{*}{ RPTest 09} & $\mathrm{~F}_{\mathrm{IT}}$ & $-0,0365$ & $-0,0074$ & 0,0007 & $-0,0209$ \\
\hline & $\mathrm{F}_{\mathrm{ST}}$ & 0,0126 & 0,0547 & 0,1881 & 0,0421 \\
\hline & $\mathrm{F}_{\mathrm{IS}}$ & $-0,0498$ & $-0,0657$ & $-0,2308$ & $-0,0658$ \\
\hline \multirow[t]{3}{*}{ PR 4.6} & $\mathrm{~F}_{\mathrm{IT}}$ & 0,4261 & $-0,1139$ & 0,2275 & 0,2513 \\
\hline & $\mathrm{F}_{\mathrm{ST}}$ & 0,2036 & 0,0775 & 0,1518 & 0,1608 \\
\hline & $\mathrm{F}_{\mathrm{IS}}$ & 0,2794 & $-0,2074$ & 0,0892 & 0,1079 \\
\hline \multirow[t]{3}{*}{ PSM 2} & $\mathrm{~F}_{\mathrm{IT}}$ & 0,0576 & 0,0576 & - & 0,0576 \\
\hline & $\mathrm{F}_{\mathrm{ST}}$ & 0,0205 & 0,0205 & - & 0,0205 \\
\hline & $\mathrm{F}_{\mathrm{IS}}$ & 0,0380 & 0,0380 & - & 0,0380 \\
\hline \multirow[t]{3}{*}{ MÉDIA } & $\mathrm{F}_{\mathrm{IT}}$ & & & & 0,0423 \\
\hline & $\mathrm{F}_{\mathrm{ST}}$ & & & & 0,0901 \\
\hline & $\mathrm{F}_{\mathrm{IS}}$ & & & & $-0,0525$ \\
\hline
\end{tabular}




\section{CONCLUSÕES}

1. Primers de locos microssatélites, desenvolvidos para Pinus strobus, $P$. radiata, $P$. silvestris e P. taeda foram transferidos para o $P$. caribaea var hondurensis com sucesso.

2. No decorrer das etapas do programa de melhoramento, houve perda dos alelos de baixa freqüência, tendo como conseqüência o aumento da freqüência dos alelos mais comuns.

3. Analisando as populações-base, selecionada e melhorada $\mathrm{F}_{1}$, observou-se maior fixação entre $\left(F_{S T}=0,0213\right)$ e menor fixação dentro de populações $\left(\mathrm{F}_{\mathrm{IS}}=-, 0061\right)$.

4. A maior distância genética $(\mathrm{D}=0,0119)$ entre as populações estudadas foi observada entre a população-base e a melhorada $\mathrm{F}_{1}$, devido ao processo de seleção.

5. A análise da distância genética entre matrizes permitiu a indicação de 10 cruzamentos potenciais, com o objetivo de obter maior amplitude de variação.

\section{AGRADECIMENTOS}

Á Divisão Madeira da A. W. Faber-Castell S.A. pela doação do material para a realização deste trabalho e, em especial, à pesquisadora Engenheira. Eliane Fiorentini, pelo seu apoio irrestrito.

\section{REFERÊNCIAS}

BERTOLANI, F.; NICONIELO, N.; MIGLIORINI, A. J. Melhoramento genético e produção de sementes de Pinus spp na CAFMA - Agudos (SP). In: SIMPÓSIO INTERNACIONAL: MÉTODOS DE PRODUÇÃO E CONTROLE DE QUALIDADE DESEMENTESE MUDASFLORESTAIS, Curitiba, 1984. Anais... Curitiba: FUPEF, 1984. p. 478-494.

BROWN, A.D.H.; WEIR, B.S. Measuring genetic variability in plant population. In: TANKESLEY, S. D., ORTON, T. J. (Eds.). Isoenzymes in plant genetics and breeding. Part A. Amsterdam: Elsevier Science, 1983. p. 219-239.

ECHT, C. S.; MAY-MAQUARDT, P.; HSEIH, M.; ZAHORCHAK, R. Characterization of microsatellite markers in eastern white pine. Genome, Ottawa, v.31. ,p.1102-1108, 1996.

ECHT, C. S., BURNS, R. (1999). SSR derived from Pinus taeda ESTs. Disponível em: http:/ / dendrome.ucdavis.edu/Data/ssrest.html. Acesso em 2/8/2004.

ELSIK, C. G., MINIHAN, V. T., HALL, S. E., SCARPA, A. M., WILLIAMS, C.G. Low-copy microsatellite markers for Pinus taeda L. Genome, Ottawa, v. 43, p. 550-555, 2000.
ESTATISTICAS. Disponível em: http://www.sbs.org.br/ estatisticas.htm. Acesso em 2 ago. 2004.

FERREIRA, M. E.; GRATTAPAGLIA, D. Introdução ao uso de marcadores moleculares em análise genética. Brasília: EMBRAPA-CENARGEM, 1998. 220p.

GOLFARI, L. Distribuicón geográficas de las plantaciones de Pinus caribaea Morlet em Argentina, Uruguay, Paraguay y Brasil. In: JORNADAS SOBRE PINUS CARIBEA. Anais... Eldorado, Missiones, Argentina: Universidad Nacional de Santiago, 1991. p.164-173.

GRIFFITHS, A. J. F., MILLER, J. H., SUZUKI, D. T., LEWONTIN, R. C., GELBART, W. M. Introdução à Genética. New York: W.H. Freeman; Guanabana Koogan, 2002. 743 p.

HAMRICK, J. L. Allozyme diversity of natural stands versus seed orchard Loblolly Pine. In: MEETING AND ACTIVITY REPORTS OF THE CANADIAN TREE IMPROVEMENT ASSOCIATION, 23., 1991, Otawa. Proceedings... Otawa: Canadian Tree Improvement Association, 1991. p.21.

HICKS, M.; ADAMS, D.; O'KEEFE, S.; MACDONALD, E.; HODGETTS, R. The development of RAPD and microsatellite markers in lodgepole pine (Pinus contorta var. latifolia). Genome, Ottawa, v. 41. p. 797-805, 1998..

KOSTIA, S., VARVIO, S., VAKKARI, P., PULKKINEN, P. Microsatellite sequeces in a conifer, Pinus sylvestris. Genome, Ottawa, v.38. p.1244-1248, 1995.

MILLER, M.P. Tools for population genetic analysis (TGFPA). 1.3. A Windows program for the analysis of allozime and molecular population genetic data. Computer software distributed by the author. 1997.

MORI, E. S. Variabilidade genética em uma população de Eucalyptus grandis Hill ex Maiden submetida a diferentes intensidades de seleção. 1993. 119 f. Tese (Doutorado) - Escola Superior de Agricultura "Luiz de Queiroz", Piracicaba, 1993.

MOURA, V. P. G.; DVORAK, W. S. Provenance and family variation of Pinus caribaea var. hondurensis from Guatemala and Honduras, growth in Brazil, Colombia and Venezuela. Pesquisa Agropecuária Brasileira, Brasília, v. 36, n. 2, p. 225234, 2001.

NEI, M. Genetic distance between populations. American Naturalist, Chicago, v. 106. p. 283-292, 1972.

NEI, M. Estimation of average heterozygosity and genetic distance from a small number of individuals. Genetics, Ottawa, v. 89, p.438-443, 1978.

ROCHA, R. B., MURO ABAD, J. I., PIRES, I. E, ARAÚJO, E. F. Fingerprint and genetic diversity analysis of Eucalyptus ssp. genotypes using RAPD and SSR markers. Scientia Forestalis, Piracicaba, v. 62. p. 24-31, 2002.

SHEPHERD, M.;CROSS, M.; DIETERS, M. J.;HENRY, R. Genetic maps for Pinus elliottii var. elliottii and P. caribaea var. hondurensis using AFLP and microsatellite markers. Theoretical and Applied Genetics, Berlin, v. 106, p. 1409-1419, 2003. 
SHEPHERD, M.; CROSS, M.; MAGUIRE, T. L.; DIETERS, M.J.; WILLIAMS, C.G.; HENRY, R.J. Transpecific microsatellites for hard pines. Theoretical and Applied Genetics, Berlin, v. 104, p. 819-827, 2002.

SMITH, J. S. C. \& DEVEY, M. E. Occurrence and inheritance of microsattelites in Pinus radiata. Genome, Ottawa, v.37, p. 977983, 1994.

WEBER, J., STELZER, H. Operational Rooted Cuttings in Southern Pines. In: WESTERN FOREST AND CONSERVATION NURSERY ASSOCIATION CONFERENCE, 2000, Kailua-Kona. Proceedings... Kailua-Kona: Western Forest and Conservation Nursery Association, 2000. p. 91-92.
WENDLING, I., XAVIER, A. Gradiente de maturação e rejuvenescimento aplicado em espécies florestais. Floresta e Ambiente, Rio de Janeiro, v. 8., n. 1., p. 187-194, 2001.

WILLIAMS, C. G.; HAMRICK, J. L. Niveles de diversidad genetica en un programa de generacion avanzada de Pinus taeda L., medidos con el uso de marcadores moleculares. Forest Genetics Resource Information, Roma, n. 23, p. 50-56, 1995.

WRIGHT, S. The interpretation of population structure by Fstatistics with special regard to system of mating. Evolution, Lawrence, v. 19, p.395-342, 1965. 